\title{
Radio Frequency Identification, an Efficient Modern Technology or a Huge Threat in the Aviation Industry
}

\author{
Seyed Mohammad Serajzadeh \\ Department of computer Science, \\ Bahmanyar higher Education center, \\ Kerman, Iran
}

\author{
Omid Pourgalehdari \\ Department of computer Science, \\ Islamic Azad University, Rafsanjan Branch, \\ Rafsanjan, Iran.
}

\begin{abstract}
Human is striving for a well-facilitated world on a daily basis. Having been invented for more than half a century, Radio frequency identification or RFID is lately being used. While noting that every new technology comes along with its threats, RFID technology is bound to the same rule. This paper examines the possible threats of this technology and introduces ways to counter these threats and finally concludes that RFID system is a suitable technology for aviation industry due to the costs and the discussed threats and problems.
\end{abstract}

\section{Keywords}

Radio frequency, RFID, threat, detection, aviation technology

\section{INTRODUCTION}

Today all companies are competing against each other to present better services with high quality in lower price to attract more customers. Using high tech devices enables the companies to win this competition. When RFID was used in supply chain management such as: controlling the production and consumption procedure from the beginning to the end, preventing theft, increasing instant inventory control efficiency and decreasing the transporting and shipping costs, it became one of the influential factors of tracing and shipping goods in aviation transportation. Considering the growth in air travel rate, the airports provide passengers with various services and since the growth of the passengers' number will increase the chance of error, airports are seeking ways to reduce human errors yearly. Hong Kong International Airport in 1990s was one the pioneers in using RFID technology which came as a replacement for infrared system and barcode [1]. Nowadays many airports are equipping themselves with RFID technology but the question is if RFID is a rational technology considering the high costs and the possible threats and problems.

\section{RFID TECHNOLOGY}

RFID is not a brand new technology as it goes back to World War II which was used as a detection device for enemy or ally planes [2]. In this technology, data can be transferred between the transmitter and the receivers by the radio frequency, containing numbers or any other information and that is why, this technology is more popular than inferred or barcode. Today RFID has found a remarkable status in E-commerce. In the last 20 years, the number of mobile users as means for Ecommerce and trading goods has risen drastically [7]. According to the statistics in May 2013, approximately 53\% of American citizens were using smart phones which almost all of them has access to the internet. With the development of the mobile performance, the RFID usage has also become important that every day one can see many goods with RFIDs being stuck on them therefore, mobiles, as available devices can be used as means for RFID technology.

\subsection{RFID Equipments}

Tags are one of the fundamental equipment of RFID technology. These tags have a radio frequency transmitter which the data is read by a special device, reader. The data can simply contain the good's identification code or price and by the use of the reader, the data is processed by the computer. These tags are attached to the goods which by this the good's identity and its place can be traced at any time [4]. Antennas are another important piece of equipment for RFID technology which by getting connected to the readers, enhance the connection limited area between the readers and the tags [6]. Tags are divided into three categories: active, passive and battery-assisted passive. While active tags contain a small battery to produce electricity for transmitting and receiving radio frequencies, passive tags have no energy source therefore they get energy from receiving frequencies. The battery-assisted passive tags have electric energy themselves but need radio frequency to be enabled [5].

\subsection{RFID Costs}

RFID tags save more data than barcodes, besides; the data from different tags can be read simultaneously without human intervention in a shorter period of time; the advantage which can never be found in barcode since barcodes must be read individually by the help of human. Considering the advantages of tags in comparison to barcodes, it brings up the question of why after almost 50 years of tag and RFID's invention, what took it so long to use this technology in Ecommerce? The answer to this question is only the costs and the expenses [2]. The RFID technology cost is divided into three main categories, the hardware costs, the firmware costs and the service costs. The first category is chiefly the costs of all tangible devices necessary for this technology such as: tags, readers, antennas and other preforming devices. The second category includes the software and infrastructure costs to make the best use of this technology. Undoubtedly, the higher software architecture and infrastructure quality, the less chance of making errors and consequently the system will lead us towards the final purpose which increases the economic profitability. The last category is the business process designing costs and the system configuration expenses [9].

\subsection{Problems And Threats}

Due to the enormous growth of RFID technology, especially in sensitive fields such as passports or credit cards with these especial chips designed for these purposes, the importance of this technology can be noticed easily. Companies and tag users and customers need to consider some tips [10]. Every new technology is endanger of threats and problems coming 
from the environment and Radio networks like wireless system or RFID system face with more serious threats in comparison to the others and this is only because of the easy availability of these systems for communication channel hackers. One of the chief problems of RFID technology is the lack of international standard which has influenced the system performance. For instance, the companies, located in Europe, creating RFID related devices such as tags and readers all work with ISO however, other producers elsewhere use other Standards such as Electronic Product Code (EPC). This standard diversity makes the devices of different companies difficult to work with each other.

Another noteworthy problem of this system is its user environment. Today most of tags work with radio frequency of 13.56 or 915 megahertz which liquids such as water, absorb these frequencies and create problems for RFID system. Moreover, the glue which is used to stick tags on goods weakens the frequencies as well. Metals also stop and reflect the radio frequencies [11]. Above all these problems, there are also external issues such as several attacks to these systems. One of the most distinguished attacks is called 'the deactivation' which deletes the tags data by sending frequencies therefore the readers will be unable to detect the tags and read the data [12].

\subsection{RFID Security Methods}

Since RFID system has become an inseparable part of human's daily life, the security of privacy and identifying the RFID chips are the most important things to be considered. The new technology of disposable identification codes which is connected to the intensive data base has developed the security needs [10] however, people's concerns over the usage of RFID has not been eased yet. The table below shows the people's concern of RFID system in Europe and America [12]:

Table 1. people's concern of RFID system in Europe and America

\begin{tabular}{|l|l|l|}
\hline Cause & $\begin{array}{l}\text { The } \\
\text { US } \\
\%\end{array}$ & $\begin{array}{l}\text { Europe } \\
\%\end{array}$ \\
\hline Reutilizing the customers' data & 69 & 59 \\
\hline $\begin{array}{l}\text { Tracing customers by using the bought } \\
\text { items }\end{array}$ & 65 & 55 \\
\hline Far distance tag identification & 42 & 52 \\
\hline Being more objective by direct marketing & 67 & 52 \\
\hline Environmental effects & 45 & 44 \\
\hline The frequencies effect on human health & 56 & 35 \\
\hline RFID tags that can be eaten/dissolved & 43 & 31 \\
\hline
\end{tabular}

While there are too many threats for this technology, the security expert teams have been trying to improve the security aspect of RFID technology. Today many of these threats have been removed such as empowering the security system of radio frequency identification using the pubic key. The public key is a significant help in preserving the users' identity and good's data on tags. Using passwords for decoding the tags' data is another noteworthy method of security which gives no access to those without the permission. However, the passwords must be carefully protected because by finding the passwords, hackers will be able to steal the data. To develop the security system, metal covers or foils can be used as well which protects tags from all external attacks; this method is called 'Faraday cage'. RSA coding system, creating hash codes for tags' data, using pin codes and destroying tags after being used are the other various methods of RFID security system.

\section{AIRPORTS}

Nowadays people are using public transport more than before which air travel is the most popular one. Due to the America Central Intelligence Agency statistics in 2013, there are about 41.821 airports in the world [15] which according to the International Air Transport Association, IATA, there has been more than 34.7 million flights containing about 2.98 milliard passengers, that year. It is not only about transporting passengers but also transporting their luggage and other cargoes. It worth mentioning that there has been 6.3 trillion dollars of value in transporting goods by aviation industry which is equal to one third of the value of all goods transported by other transportation modes in the world [14]. Iranian airports also have a substantial contribution in transportation industry. Having 319 airports, Iran has been rated as the $22 \mathrm{~d}$ in the list of countries with airports and being on top of many other developed countries such as Japan, Sweden, Spain, Finland, Italy, Norway and Swiss shows the popularity of this industry.

\subsection{Air Cargo Transportation Costs}

Air cargo transportation came along simultaneously with passengers flights. On 14th of November 1919, American Railway Express sponsored air cargo transportation for the first time which was not successful due to the emergency landing. However, in 1925, Ford Motor Company transported the first air cargo successfully and after that the American Railway Express started its air activities in 1927 [18]. Air transportation, passenger or cargo, has been considered as costly in comparison to land and water transportation. Air cargo transportation has had a considerable growth over the last recent years; in 1980 there has been 11 million tons of transported cargo which rose to 49 million tons in 2011 which means this industry has the growth of $4.9 \%$ in yearly basis which is way more than the yearly growth of water cargo transportation rate by $2.9 \%$. 1.1. Air Cargo Transportation Costs are divided into two chief groups: direct and indirect:

Direct Costs include:

- Fuel Costs

- Crew Costs

- Airports taxes for taking off and landing

- Renting Plane Costs

- Keeping and Repairing Planes Costs

- Planes Insurance

Indirect Costs include:

- The employees' Salary in company offices

- $\quad$ Storage Costs

- Equipment Costs

Obviously the high expenses have not affected the popularity of this industry since the transportation quality, speed and the cargo insurance have covered the expenses [16]. According to the World Bank data, each 1 kilo of air cargo transportation is 4 to 5 times more expensive than land transportation and 12 to 
16 times more than water transportation which is approximately 4 USD [17]

\subsection{Damaged Passengers Baggage}

Air Transportation Companies, despite their constant efforts, cause damages to passengers' baggage for numerous reasons like employees' negligence. This damage can vary from a small crack on the passengers' suitcase or losing the whole package. Yearly, these companies pay considerable amounts to compensate for these cases; according to the statistics, every year about 12 million suitcases are lost which many of them will be found and sent back to their owners however still many of them stay missing. In 2010 about 1 million suitcases were reported missing and they were never found. In average, losing and baggage, finding and sending it to the owner costs about 100 dollars. In 2012, America lost baggage of passengers with the value of 3 milliard dollars which this number has grown 177 times in the last 5 years; this soaring rate shows the necessity of improving the service quality for companies [19].

\subsection{Barcode And Its Problems}

Comparing barcode and RFID technology is not easy since their differences are not on the same level [20]. Barcode technology uses light to transfer the data; however, the RFID technology uses radio frequencies [2]. The most noticeable barcode problems can be summed up as follows:

- Optical Scanning Implications: The barcode reader uses direct 'line-of-sight' to scan a barcode otherwise the data cannot be processed.

- Limited sight and distance: The distance between the reader and the barcode cannot be far.

- Individual Scanning: each barcode must be read individually which slows down the process while by RFID technology several tags can be scanned simultaneously and accurately.

- Tracing Ability: Tracing goods with RFID tags is much easier than those with barcodes.

- Prone to human errors: Since barcode technology massively depends on human interference, it increases the error percentage.

These are only a few barcode system used in companies, organizations and public areas [20].

\subsection{RFID in Airports}

In the last decade, RFID technology has become a popular industry due to its numerous advantages. On the other hand, the rising numbers of flights, passengers and their baggage have put Airline Companies into more trouble [21]; therefore companies are seeking new ways to provide customers with better service quality which one of them is utilizing RFID technology. RFID technology marketing rate in airports has risen from 20 million dollars to 100 million dollars from 2006 to 2016 proving the airports essential need for this technology. Another remarkable feature of RFID technology is that it enables the airline companies to categorize the baggage according to the baggage owner, final destination and instant tracing. At the moment, Hong Kong International Airport, British Airline, Delta Airline and Singapore Airlines are replacing barcode system with RFID which due to their own policy, each use one of the two popular RFID technologies. In the first model, cheap tags are used that can save limited piece of data such as the passenger's identity, baggage number, origin and destination which it can be updated once the tag is connected to the data processing systems. One of the biggest concerns for this technology is when the systems are disconnected.

In the second model, expensive tags are used which can save more data due to their huge capacity and do not depend on data processing systems as much. On each section of the transportation process new data will be saved on tags. One of their main advantages is that they can be used again [22]

Using RFID technology enables the airlines and the passengers to trace their baggage via internet and in cases of baggage loss, find it as soon as possible.

\section{CONCLUSION}

The purpose of this study was to study RFID technology and its place in aviation industry and finally, considering its high costs, is replacing barcode technology with RFID a reasonable action? It seems almost irrational not to use RFID technology since air cargo and passenger transportation is getting more popular in the last recent years according to the statistics. RFID technology costs are divided into two categories; the first costs are the initiation costs and the second are the current expenditures including tags' purchasing and the repair costs. Considering the baggage damage costs which the airlines pay to the customers, using RFID technology instead of barcode is absolutely rational. The profit made by using this technology is enough to cover the expenses costs for replacement which makes airlines, air cargo transportation companies more efficient.

\section{REFERENCES}

[1] Y F Wong, Paul W K Wu, Daniel M H Wong, Denny Y K Chan, L C Fung, S W Leung, RFI Assessment on Human Safety of RFID System at Hong Kong International Airport, Hong Kong Airport Authority, Hong Kong SAR, China

[2] Albert Lozano-Nieto, RFID Design Fundamentals and Applications

[3] Roy Want , An Introduction to RFID Technology, PERVASIVE computing magazine Published by the IEEE CS and IEEE Computer Society

[4] Ron Weinstein, RFID: A Technical Overview and Its Application to the Enterprise , IT Pro magazine published by the IEEE computer Society

[5] Mayadah Hassan, Dr. Maged Ali, Dr. Emel Aktas, Radio Frequency Identification (RFID) Technologies for Locating Warehouse Resources: A Conceptual Framework, Brunel Business School, Brunel University, London, United Kingdom.

[6] Roger Smith , RFID: A Brief Technology Analysis, CTOnet.org (C) Copyright 2004

[7] Weiping Zhu, Dong Wang, Huanye Sheng, Mobile RFID Technology for Improving M-Commerce, Dep. Of Computer Science \& Engineering, Shanghai Jiaotong University

[8] Liran Einav, Jonathan Levin, Igor Popov, Neel Sundaresan, Growth, Adoption, and Use of Mobile ECommerce, American Economic Review: Papers \& Proceedings 2014, 104(5): 489-494

[9] Serdar Baysan and Alp Ustundag, The Value of RFID, Chapter two, Springer-Verlag London 2013 
[10] Gurudatt Kulkarni, Ramesh Sutar and Sangita Mohite, RFID Security Issues \& Challenges, 2014 International Conference on Electronics and Communication System

[11] RFID Adoption: Issues and Challenges, Eric W. T. Ngai, The Hong Kong Polytechnic University, PR China.

[12] RFID Technologies: Emerging Issues, Challenges and Policy Options, Marc van Lieshout, Luigi Grossi, Graziella Spinelli, Sandra Helmus, Linda Kool, Leo Pennings, Roel Stap, Thijs Veugen, Bram van der Waaij, Claudio Borean, European Commission Joint Research Centre Institute for Prospective Technological Studies

[13] RFID Security, The Government of the Hong Kong Special Administrative Region, February 2008

[14] IATA Annual Review 2013, International Air Transport Association

[15] The World Factbook, Central Intelligence Agency (CIA), United States of America, 2015

[16] Cost analysis of air cargo transport and effects of fluctuations in fuel price, Ching-Cheng Chao, ChingWen Hsu, Department of Shipping and Transportation Management, National Kaohsiung Marine University, Taiwan, ROC
[17] The World Bank, international financial institution, Washington D.C., United States

[18] Liability problems of air cargo carriage, charles S. Riryn, Aeronautical Law Committee of the American Bar Association

[19] The problem with airlines and checked baggage, Barbara Peterson, conde nast traveler mag, june 2012

[20] The Advantages and Disadvantages of Barcodes and Radio Frequency Identification in Supply Chain Management, Luke McCathie, Dr Katina Michael, School of Information Technology and Computer Science, University of Wollongong, 2004

[21] Application of rfid in aviation industry: an exploratory review, ALOK MISHRA, Ph.D, DEEPTI MISHRA, Ph.D, Atilim University, Department of Computer Engineering, Ankara, Turkey

[22] Traceable Air Baggage Handling System Based on RFID Tags in the Airport, Ting Zhang, Yuanxin Ouyang, Yang $\mathrm{He}$, School of Computer Science and Engineering, Beijing University of Aeronautics and Astronautics, China, 2008 